\title{
INSURGÊNCIA PERIFÉRICA E A TEORIA CRÍTICA DAS RELAÇÕES INTERNACIONAIS
}

\author{
Jaime Cesar Coelhoa \\ aProfessor titular do Departamento de Economia e Relações Internacionais da Universidade Federal \\ de Santa Catarina (UFSC). Florianópolis, SC, Brasil.E-mail: findariver@gmail.com \\ Orcid: 0000-0003-4492-4259 \\ Laura Mabel Lacaze ${ }^{b}$ \\ ${ }^{b}$ Mestre em Relações Internacionais pela Universidade Federal de Santa Catarina (UFSC). \\ Florianópolis, SC, Brasil.E-mail: lauralacaze@gmail.com \\ Orcid: 0000-0001-6268-9649 \\ http://dx.doi.org/10.1590/0102-249273/111
}

\section{Introdução}

Neste artigo, propomos ensaiar uma vinculação entre a produção teórica de Robert W. Cox e de Álvaro García Linera. Esse exercício de comparação teórica se insere no campo da economia política internacional crítica, de corte neogramsciano (Cox), desenvolvida a partir do campo de estudo das relações internacionais e da perspectiva crítica latino-americana de inspiração marxista (Linera), cara aos estudos transdisciplinares da sociologia, da ciência política e da economia política. Assim sendo, o objetivo geral deste artigo é procurar aproximações entre a abordagem de crítica neogramsciana, que se supõe ter seu ponto forte na caracterização da ordem mundial contemporânea, e a perspectiva regional (local), crítica, que trata da inserção latino-americana dentro dessa ordem mundial.

Apesar das distâncias que separam suas origens e seus percursos, ambos os autores compartilham duas inquietações fundamentais: a caracterização da ordem mundial vigente, hierárquica politicamente e assimétrica materialmente, 
e sua transformação em uma estrutura cujos elementos constitutivos sejam a pluralidade cultural e a igualdade material.

Os autores vêm de duas realidades geopolíticas tão diversas quanto podem ser a do Canadá e a da Bolívia. Suas trajetórias pessoais, tanto no âmbito político quanto no profissional e intelectual, também evidenciam marcadas diferenças. Cox é um homem do norte desenvolvido, que fez sua carreira na Organização Internacional do Trabalho (OIT) até ingressar na academia, onde viria a desenvolver seu plano de pesquisa, inicialmente sobre as organizações internacionais, até culminar em sua obra sobre as ordens mundiais. A autobiografia de Cox (2013) tem o título de Estrangeiro Universal, ${ }^{1}$ uma forma muito peculiar do autor referir a si como alguém que está no mundo, que sempre esteve de alguma forma como estrangeiro tanto em seu país como na ordem capitalista vigente. O campo de ação de García Linera foi (e ainda é), fundamentalmente, o âmbito político 250 boliviano. Pode-se dizer, sem erro, que García Linera é propriamente um teórico da ação, alguém que mescla o olhar atento do intelectual com o compromisso da ação política direta. Participou da luta armada, do processo que derivou nos levantamentos populares do ano 2000 na Bolívia e, finalmente, integrou como candidato à vice-presidente a chapa que no ano de 2005 levou ao poder o primeiro presidente indígena da história da Bolívia, Evo Morales. ${ }^{2}$

Para os autores, o poder político das ideias, da cultura, portanto, da intersubjetividade na conformação das expectativas dos atores sociais, cumpre um relevante papel na estruturação do poder entre as classes sociais. Ambos identificam no âmbito das ideias um campo de disputa de poder, sendo, assim, o desenvolvimento teórico uma ferramenta para a ação orientada à alteração dos padrões existentes.

\footnotetext{
1 No original: The universal Foreigner: the individual and the world.

2 Cabe ressaltar que este artigo começou a ser escrito antes dos trágicos acontecimentos que levaram à deposição forçada de Morales e Linera no ano de 2019.
} 
Seus construtos se baseiam em uma matriz comum caracterizada pelo marxismo, incluindo-se, sobretudo, as contribuições de Gramsci, embora García Linera incorpore ademais os conceitos de Bourdieu como outra contribuição fundamental de seu marco interpretativo.

Começaremos o artigo, então, apresentando as características salientes das conceitualizações elaboradas por cada um dos autores sobre a questão da ordem. Consideramos esse ponto de importância fundamental, sobretudo levando-se em consideração que a obra de Robert Cox é sensivelmente mais difundida que a de García Linera no campo das relações internacionais. Posteriormente, faremos uma releitura desses marcos interpretativos, procurando salientar os pontos de contato e de divergência entre eles. Por fim, buscaremos identificar a problemática da transformação da ordem internacional a partir de ontologias semelhantes a partir do ponto de vista da influência intelectual, porém muito diferentes desde a trajetória de vida dos autores e de suas origens geográficas. A experiência no âmbito das organizações internacionais de Cox e a experiência prática na transformação boliviana são peças de um quebra-cabeças da ordem internacional que pode lançar luzes na construção da teoria crítica e de suas consequências práticas em termos da ação transformadora.

\section{Cox, um estrangeiro universal}

Cox é um autor que inicia sua vida profissional no exato momento em que emerge a institucionalidade da pax americana, a partir da emergência do sistema da Organização das Nações Unidas (ONU). Diretamente envolvido nessa experiência, já em 1947 engaja-se em sua primeira experiência profissional na OIT. Embora fosse uma organização internacional criada em 1919, sob o acordo do tratado de Versalhes, a partir da segunda grande guerra ela se transforma numa agência do sistema da ONU. Será no espírito 
de construção de um mundo pacífico, por meio da institucionalidade internacional multilateral, que o jovem Cox trilhará seus primeiros passos rumo ao que viria a ser uma grande experiência e o terreno para grandes frustrações e mudanças de rumo em sua vida profissional.

Já no início dos anos 1950, estoura a Guerra Fria e progressivamente as tensões no mundo periférico se avolumam. As ilusões sobre o papel das organizações internacionais vão se desfazendo. Os eventos da década de 1960, como a Guerra do Vietnã e as incursões soviéticas no leste europeu, segundo Cox, seriam um divisor de águas para a decisão que ocorreria no começo dos anos 1970, quando aos 45 anos de idade, Cox sai da OIT e aceita o convite para lecionar na universidade de Columbia, em Nova York (Cox, 2013). Nessa época, Cox inicia um período de intensa produção intelectual que teria como ápice a publicação de Produção, Poder e Ordem Mundial: Forças Sociais na Construção da História ${ }^{3}$ em 1987, a obra mais reconhecida do autor.

É a partir desse contexto que iniciamos nossa investigação sobre as concepções de ordem e mudança em Cox.

\section{Ordem e mudança para Cox}

A primeira relação a que chamamos a atenção para compreender o conceito de ordem em Cox é a relação entre coerência e estrutura histórica, definida como um padrão coerente de interações.

A ordem é uma padronização de interações, as quais se dão sob uma roupagem e um conteúdo que expressam coerência, embora guardem contradições que, se desenvolvidas, levam à sua ruptura. A essa coerência, Cox,

\footnotetext{
3 No original: Production, power, and world order: Social forces in the making of history (Cox, 1987).
} 
seguindo Gramsci, dá o nome de estrutura histórica. ${ }^{4}$ Essa coerência diz respeito à ligação entre a dimensão intersubjetiva, simbólica/metalinguística, institucional e material. A emergência de uma linguagem comum em termos de preferências, expectativas e escolhas está associada à capacidade de uma força social, em associação com outras forças da sociedade civil, de transformar seus interesses específicos em interesses gerais.

Dada a influência gramsciana e por derivação marxista, Cox compreende a força social dentro de uma perspectiva materialista, de classe social, mas não a reduz a uma mera expressão de uma posição material específica. Embora estruturalmente delimitada, a ordem não é regida por padrões imutáveis, não é estática. Recorrendo a Vico, ${ }^{5}$ Cox ressalta o aspecto transitório, portanto histórico, da estrutura histórica. Ao recorrer ao filósofo renascentista, Cox está travando um debate com as perspectivas positivistas reducionistas, que procuram explicar os fenômenos sociais a partir de padrões invariáveis da natureza humana. Em contraposição ao positivismo, supõe-se a ordem como expressão de um padrão coerente (que, sendo coerente, não é isento de contradições) e mutável. Assim como o homem muda na sua constituição genética (natureza), as instituições que sustentam uma estrutura histórica também mudam (Cox, 2001, p. 94).

\footnotetext{
4 "uma combinação particular de padrões de pensamento, condições materiais, e instituições que tem uma certa coerência entre seus elementos. Estas estruturas não determinam as ações das pessoas em qualquer sentido mecânico, mas constituem o contexto dos hábitos, pressões, expectativas e constrangimentos sob os quais aquelas ações tomam lugar" (Cox, 2001, p. 97, tradução nossa).

${ }^{5}$ Gianbattista Vico, pensador renascentista italiano. Interessante observar que Cox afirma em entrevista concedida a Ana Saggioro Garcia e Miguel Borba de Sá (2009), que foi a partir de Vico que ele chega a Gramsci: "Eu cheguei a Gramsci talvez por meio de Vico. Meus estudos tinham sido na história. Eu nunca obtive uma formação em ciência política, somente ensinei ciência política. Eu fui professor, mas nunca estudei ciência política oficialmente" (Garcia e Sá, 2013, pp. 305-306, grifo nosso).
} 
Considerar a ordem como transitória e cambiável é parte constitutiva da teoria crítica, de qualquer teoria crítica; em Cox, essa perspectiva radicaliza-se à medida que ele estabelece uma relação entre o homem e a natureza, a história socialmente construída e a vida biológica como um corpo só, como pertencentes ao universo que se modifica seja pela ação consciente ou pela práxis da vida social, com suas contradições.

A mudança não obedece a um padrão pré-estabelecido em direção a um fim determinado. Ela resulta da disputa entre diferentes forças sociais num determinado contexto. Deriva-se daí uma perspectiva epistemológica que recoloca a agência como variável interveniente e não simplesmente reflexa.

Podemos abstrair a partir de Cox que a mudança é a condição humana, é a única variável constante, mas conceber a vida social como um contínuo de possibilidades dinâmicas não é a mesma coisa que concebê-la como uma colcha de retalhos mergulhada num mar caótico no qual não existe controle e ordem. Se assim fosse, a vida seria impossível, as instituições não teriam existência. A concepção ontológica subjacente em Cox tem implicações epistemológicas claras: ela consiste em conceber a teoria social como uma produção narrativa consciente, mesmo que sua reprodução possa dar-se sob uma condição acrítica, conduzida por um universo de significantes e significados socialmente constituídos de fora para dentro do indivíduo.

A teoria é sempre "feita por alguém" com algum propósito definido, em conformidade com interesses que emergem numa condição social dada materialmente. No caso do modo de produção capitalista, os interesses estão ancorados em relações sociais de produção geneticamente plasmadas pelo antagonismo, conformando uma sociedade de classes. A sociedade de classes é uma sociedade de exploração, antagônica e conflituosa. A teoria não é neutra porque a sociedade 
não é um espaço harmônico, ao contrário, a vida social numa sociedade dividida em classes sociais é conflituosa.

O trabalho teórico, das chamadas teorias de soluções de problema, ${ }^{6}$ reside precisamente em criar imagens coletivas que naturalizem relações que são transitórias, portanto, contextuais.

A ideologia procura transformar interesses antagônicos em interesses reconciliáveis. Ao contrário da teoria de solução de problemas, a perspectiva crítica é, sobretudo, subversiva, pois pretende desnudar o véu ideológico que mascara as relações sociais, mas ela não pode se contentar em simplesmente denunciar, pois o imperativo ético reside em criticar o status quo apontando para uma nova práxis social, para a superação dos padrões de sociabilidade vigente por uma nova ordem. Nesse sentido, a teoria crítica também é uma teoria de solução de problemas, mas não no sentido de dar solução para a continuidade do status quo, mas para apontar soluções no sentido da superação da ordem vigente. Deduz-se, pois, que a ordem a ser superada é a ordem capitalista e não qualquer ordem, pois a sociedade não prescinde do ordenamento, de um quadro de referências e de instituições que deem coesão mínima à existência coletiva.

A teoria em Cox é um elemento fundamental pois ela é compreensão do mundo e perspectiva de ação, de ação elaborada, consciente e estratégica.

A práxis é a síntese dessa interação entre o intelectual e seu engajamento, ou seja, a organicidade. No caso da perspectiva crítica advogada pelo autor, a organicidade representa o compromisso do esforço reflexivo por desvendar o "discurso

\footnotetext{
${ }^{6}$ A teoria de solução de problemas "toma o mundo como o encontra, com suas relações sociais e de poder prevalecentes e as instituições nas quais estão organizadas $[\ldots]$. O principal objetivo para a problem solving é fazer as relações e as instituições funcionarem adequadamente tratando efetivamente com as fontes particulares dos problemas" (Cox, 2001, p. 88, grifo nosso). Não está no horizonte da teoria de solução de problemas questionar a ordem, mas conservá-la, solucionando os problemas que ela apresenta a partir das forças sociais dominantes.
} 
natural", o discurso das coisas que parecem naturais, posto que representativas da ordem. A ordem é a estrutura, que historicamente se constitui. A ordem e a mudança são as duas faces da condição da vida social. Não há natureza nem organização da vida que sejam estáticas, eternas. A expressão da ordem é o discurso hegemônico, que decifra a mentalidade de um tempo. Pode-se dizer, com Cox, que a história humana é a história das mentalidades, mas não do real como produto do desejo abstrato, mas como uma mescla de discurso e práxis que se reproduzem mutuamente, cujo amalgama são as instituições.

O marco da ação é o terreno concreto de uma estrutura histórica, que por sua vez é uma síntese que combina capacidades materiais, ideias e instituições, na qual economia, cultura e política se combinam (Cox, 2001, p. 98).

As capacidades materiais podem ser dinâmicas (tecnológicas e organizativas) e estáticas, no sentido de dadas num certo tempo, como resultado concreto medido em termos de riqueza 256 de uma dada combinação tecnológica e organizacional. ${ }^{7}$

As ideias têm uma dimensão intersubjetiva e uma dimensão coletiva. A primeira remete ao espaço comunicativo das relações interpessoais, de ordem primária, no âmbito dos hábitos e expectativas compartilhadas de comportamento; a segunda dimensão se refere às imagens coletivas que são plurais, pois são representativas de metalinguagens que compõem projetos de mundo. Essas dimensões estão associadas, embora uma não esteja totalmente reduzida à outra. Hábitos podem prevalecer sobre alterações em imagens coletivas desde que não interfiram de forma direta nessas alterações. Regimes de acumulação se alteram sem que impliquem alterações completas de significados intersubjetivos, embora seja esperado que

\footnotetext{
7 Sob esse aspecto, poderíamos utilizar complementarmente a linguagem da teoria da regulação francesa, como uma forma de dar precisão contextual à abstração coxiana e, assim, pensando nos regimes de acumulação sucessivos de um dado modo de produção.
} 
haja alguma coerência entre as diferentes dimensões institucionais da vida social.

Instituições, para Cox, são sobretudo o amalgama de ideias e capacidades materiais e influem no desenvolvimento das ideias e das capacidades materiais. Têm um papel fundamental no exercício da hegemonia e minimizam o uso da força na resolução dos conflitos, entendendo-se as instituições como mecanismos de regulação e de normatização das interações. Mesmo instituições coercitivas têm esse papel, de economia do uso da força, pois a própria presença enquanto instituições legítimas de coerção implicam na dissuasão da violência.

Tomando como base essa síntese, Cox parte para o método da análise das estruturas históricas, que são compostas por três níveis que se relacionam de forma dinâmica: as forças sociais, as formas de Estado e as ordens mundiais. Para fazê-lo, Cox procura trazer para o plano da análise internacional a análise de Gramsci sobre a hegemonia e o poder. A hegemonia é entendida, assim como em Gramsci, como uma estrutura de poder baseada no consenso e na legitimidade de um grupo social em fazer valer seus interesses como interesses gerais. É preciso salientar que uma ordem mundial não necessariamente é hegemônica. Tanto mais próxima de uma ordem hegemônica será a estrutura que combinar de forma mais coerente instituições, ideias e capacidade material. A ordem emerge da tensão entre as forças sociais e da capacidade de ordenamento que tem determinada força social. A hegemonia não se constitui como uma derivação automática do acúmulo material, ela é produto de uma combinação e não pode prescindir das dimensões institucional e ideacional.

Quando Cox recorre à Gramsci para definir a estrutura histórica e a forma como se dá o ordenamento social, precisa resolver o problema de uma formulação intelectual que foi desenvolvida, em Gramsci, para pensar o espaço doméstico sendo que seu olhar está apontando para o ambiente internacional. 
Influenciado por sua trajetória de vida, em que exerceu até os 45 anos de idade importantes funções na OIT, o autor vê na ordem internacional a chave para o entendimento das relações que se desenvolvem nas formações econômicas e sociais específicas das distintas trajetórias nacionais, a que ele dá o nome de complexos Estado/Sociedade Civil. Tomando esse aspecto como suposto, podemos entender que as ordens internacionais são a extrapolação das relações de classe que no espaço doméstico se apresentam de forma limitada, clivadas pelas trajetórias históricas específicas e territorializadas. As ordens internacionais são, por sua vez, uma expressão, em escala ampliada, da luta de classes, da correlação de forças de um determinado tempo histórico que se configura na disputa entre diferentes forças sociais que emergem do mundo da produção.

Embora não desenvolva de forma sistemática o conceito de imperialismo, Cox concebe as ordens internacio258 nais como maneiras históricas específicas de regulação, de normatização de um sistema, que no modo de produção capitalista é imperial. Ele concebe, supomos, uma macroestrutura chamada Império, que envolve relações assimétricas de poder, portanto, relações de dominação e de exploração, configuradas na clássica definição de centro-periferia. Em sua conformação organizacional, da forma política, o sistema é dinâmico. Podemos, com Cox, dizer que o sistema imperial capitalista abrigou diferentes formas de ordenamento. É importante sublinhar que não necessariamente esses ordenamentos foram caracterizados por estruturas históricas caracterizadas pela hegemonia.

Cabe salientar, para efeito de comparação com a obra de García Linera, que a expansão do modo de produção capitalista, que está relacionada à exportação do ciclo completo do capital, promove uma externalização do processo decisório, que Cox concebe como internacionalização do Estado, enquanto García Linera chama de esfera desterritorializada 
de poder. A internacionalização do Estado representa a emergência de espaços decisórios, desterritorializados, autorizados e autorizativos, representados pela institucionalidade internacional (organizações e regimes internacionais). Essa institucionalidade tem uma dupla função, de coerção e persuasão, e nas palavras de Cox, referindo às organizações internacionais, permite a expansão da ordem internacional, regulando as interações, legitimando a ordem, coopta as elites dos países periféricos e absorve as ideias contra-hegemônicas adaptando-as aos interesses do status quo (Cox, 2007, p. 119).

A mudança de uma ordem é um processo que implica em localizar as relações de poder, seus mecanismos de reprodução, suas capacidades e sobre que imagens coletivas se sustentam. Implica em ver no tempo histórico como se dá a exploração, a dominação e a liderança.

\section{García Linera um político intelectual}

A obra de Álvaro García Linera constitui, simultaneamente, a expressão de um militante político e a de um acadêmico consagrado à reflexão intelectual. Sua produção inclui obras nas quais reflete sobre os movimentos sociais, sobre o indianismo, sobre a formação do Estado, entre outras questões. Autoidentificado como um "intelectual orgânico dos movimentos indigenistas", sua produção se orientou a entender, explicar e buscar respostas sobre os problemas nacionais (García Linera, 2010a). Nesse sentido,

Enquanto em algumas declarações do grupo

[Ofensiva Roja $^{8}$ ] falava-se nos partidos de esquerda

como portadores de ideologias forâneas 'transplantadas

\footnotetext{
8 Trata-se da Ofensiva Roja de Ayllus Tupakataristas (ORAT), organização política de extração indígena fundada no final da década de 1980 na Bolívia que defendia o direito de autodeterminação das nações aimara e quéchua e, também, da sua separação do "Estado burguês Boliviano" (Stefanoni, 2009, p. 15). Para um estudo aprofundado sobre os discursos desta organização em língua portuguesa pode consultar-se Freitas (2014).
} 
de Europa', Qhanachiri ${ }^{9}$ (pseudônimo de García Linera) dedicava centenas de páginas se debruçando em Marx, Engels ou Lenin para achar respostas para o problema nacional ou comunitário-campesino. (Stefanoni, 2009, pp. 16-17, tradução nossa) ${ }^{10}$

Após cursar estudos de matemática na Universidad Nacional Autónoma de México (UNAM), retorna à Bolívia no ano de 1985 em uma conjuntura de crescente organização dos movimentos campesinos e mineiros. Nesse marco, contribuiu à formação do Ejército Guerrillero Tupak Katari (EGTK), estrutura político-militar de apoio à insurgência indígena. Por esse motivo, foi encarcerado em abril de 1992, mantido temporariamente na qualidade de desaparecido e torturado pelos membros das forças de segurança do Estado boliviano. ${ }^{11}$ Nos anos da prisão, dedicou-se à reflexão sobre a teoria marxiana em conjunto com leituras sobre antropologia andina e 260 etno-história. Esse trabalho de pesquisa resultou na primeira versão, finalizada em 1995, de Forma valor e forma comunidade: Aproximação teórico-abstracta aos fundamentos civilizacionais que precedem ao Ayllu Universal (García Linera, 2010a). ${ }^{12,13}$

Nele, o autor revisa de forma exaustiva $O$ Capital de Marx, procurando estudar complementarmente as estruturas civilizacionais "do capitalismo no seu processo de adensamento material e de extensão territorial universalizante"

\footnotetext{
9 Voz aimara que significa: "Aquele que clarifica as coisas" (Stefanoni, 2009, p. 16, tradução nossa).

${ }^{10}$ No original: "Mientras en algunas declaraciones del grupo se hablaba de los partidos de izquierda como portadores de ideologías foráneas 'trasplantadas de Europa', Qhanachiri (seudónimo de García Linera) dedica centenares de páginas a hurgar en Marx, Engels o Lenin para encontrar respuestas al problema nacional o comunitario campesino."

11 Permaneceu na prisão de máxima segurança de Chonchocoro até o ano 1997 quando, sem ter cumprido a totalidade da sentença, foi libertado.

12 No original: Forma valor y forma comunidad. Aproximación teórico-abstracta a los fundamentos civilizatorios que preceden al Ayllu Universal.

13 O Ayllu constitui a estrutura comunitária aimara.
} 
e "da comunidade na sua forma histórica local e crescentemente subsumida pela lógica mercantil-colonial (a comunidade colonial e pré-colonial)". Essa leitura da forma valor como a lógica organizativa da modernidade capitalista e da forma comunidade como a lógica organizativa do mundo andino (Stefanoni, 2009, p. 17) é conduzida por um objetivo político claro: abstrair sobre a experiência histórica concreta do lugar para buscar nessa experiência a superação da "civilização do capital", a ordem universalizante (García Linera, 2010a, pp. 31-32).

Após sua libertação, atuou como professor de Sociologia, tempo no qual escreveu os livros: Reproletarización e La condición obrera. Sua projeção política ganhou uma dimensão de relevância no marco dos levantes campesinos do ano 2000, a chamada "guerra pela água" e o cerco à cidade de La Paz. ${ }^{14,15}$ Aqui se produz sua aproximação definitiva com o movimento indigenista representado, entre outros, por Felipe Quispe, líder dos aimaras do altiplano pacenho, e por Evo Morales, dirigente das Seis Federaciones del Trópico de Cochabamba. Nas eleições de 2002, pela primeira vez, os votos obtidos pelos movimentos políticos indígenas (o MAS com Morales e o MIP com Quispe) superaram qualquer outro partido político, contando ambos com o apoio de García Linera. Subsequentemente, no ano de 2005, Linera é convidado a formar parte da chapa em conjunto com

\footnotetext{
${ }^{14}$ No mês de abril do ano de 2000, e como resposta a um projeto que levaria à privatização da água, produziu-se um levante popular que mereceu uma reação marcadamente repressiva por parte do, então, governo boliviano. Esse fato, ao mesmo tempo que deixou um saldo de dezenas de feridos, constitui-se em um evento marcante para o cenário político boliviano suportando a consolidação dos movimentos políticos de extração indígena cujo desdobramento mais relevante seria o cerco sobre a cidade boliviana de La Paz sob a liderança indígena. Nesse episódio, Felipe Quispe Huanca, "El Mallku”, exigiu falar com Hugo Bánzer "de presidente para presidente" (García Linera, 2010b).

15 A cidade de La Paz constitui a sede do Governo da Bolívia, embora a capital constitucional seja Sucre. Sendo que a cidade se localiza em um vale e que as comunidades indígenas residem nas partes altas do seu entorno, o cerco se efetivou através de bloqueios dos acessos à cidade
} 
Evo Morales Ayma transformando-se em dezembro daquele ano no vice-presidente do primeiro governo indígena da história da Bolívia (Álvaro, 2015).

O exercício da função no executivo boliviano não interrompeu sua atividade no mundo acadêmico. Organizou os ciclos de seminários internacionais Pensando o mundo desde Bolívia $^{16}$ (Vicepresidencia del Estado Plurinacional, 2010, 2011), impulsionou a publicação da revista La Migraña e a edição de numerosos livros de autores contemporâneos.

A produção intelectual de García Linera adotou, nessa última etapa, formatos variados como artigos, palestras, conferências e discursos, dentre os quais se destacam, por serem de especial relevância para este artigo o livro Democracia Estado Nação $^{17}$ (2013) e as conferências A construção do Estado ${ }^{18}$ (2010b) e Estado, democracia e socialismo ${ }^{19}$ (2015), ministradas na Universidade de Buenos Aires e na Sorbonne, respectivamente.

Nas três fontes supracitadas, o autor aborda em geral o problema do Estado, tendo como eixo central de sua reflexão a ordem e sua mudança. Em relação a esse último ponto, a questão sobre a qual se debruça são as formas específicas de construção de uma estrutura de relações baseadas em um padrão alternativo ao vigente caracterizado pela pluralidade.

\section{Ordem e mudança em García Linera}

O autor propõe pensar a ordem desde o crivo analítico da estrutura de relações políticas que definem a tomada de decisões sobre o rumo coletivo. Em função da espacialidade na qual essas relações se assentam, reconhece dois níveis

\footnotetext{
${ }_{16}$ No marco desses debates, que contaram com a participação do próprio García Linera, foram convidados importantes lideranças intelectuais da esquerda mundial, dentre os quais se destacam Immanuel Wallerstein, Slavoj Žižek, Ernesto Laclau, Antonio Negri, Samir Amin e Boaventura de Sousa Santos.

17 No original: Democracia Estado Nación.

18 No original: La construcción del Estado.

19 No original: Democracia, Estado y Socialismo.
} 
na análise, contrapondo, nesse sentido, as formas estatais e supraestatais de regulação. As primeiras são caracterizadas como uma relação social territorializada, isto é, com uma abrangência espacialmente definida. Em contraste, a supraestatalidade se expressa na existência desterritorializada de fluxos econômicos e políticos de caráter global que, embora guardem relação com a administração do Estado e sua soberania, a transcendem e desafiam a dinâmica decisória interna (Linera, 2010b).

O foco da sua análise é o Estado e o que ele expressa, dois elementos interligados. Por um lado, resulta uma consequência lógica de sua história e prática concreta na esfera política, mas por outro é coerente com a centralidade que conserva o Estado em termos do comando na direção política da sociedade. Nesse sentido, para García Linera o processo chamado de globalização não configura uma tendência de extinção das formas de regulação estatal, mas de uma progressiva mutação da soberania política no qual as inter-relações desterritorializadas tem avançado sobre esferas da autonomia estatal, mas sem anulá-la.

Segundo García Linera (2010b) o Estado tem de ser pensado como um "aparelho social, territorial, de efetiva produção de três monopólios: coerção, recursos e legitimidade". O autor define como monopólio da coerção a dimensão desenvolvida por Marx e Weber do Estado como relação de dominação, isto é, de instância de reprodução de uma correlação de forças a partir das classes sociais com capacidade de influenciar ou, em outras palavras, de estabelecer uma hierarquia específica na tomada de decisões. Como "monopólio dos recursos", no sentido desenvolvido por Lenin e por Elías, o Estado representa uma forma específica de captação e aplicação do excedente econômico. Finalmente, seguindo Bourdieu, o Estado também deve ser pensado como "monopólio da legitimidade” (Linera, 2013, pp. 81-86). 
Na produção efetiva desses três monopólios intervêm três componentes ou tipos de relações:

- As de força ou estruturas do poder político, que expressam a correlação entre diferentes blocos e forças com capacidade de definir e de influenciar no processo de tomada de decisões.

- As materiais, institucionais, isto é, as estruturas do poder econômico, que se conformam através da materialização das decisões, dos resultados de cada uma dessas instâncias de disputa concreta que adotam carácter de instituições (normas, procedimentos, hierarquias, hábitos etc.).

- As ideacionais ou de poder simbólico, que se observam como regimes de crenças, como ideias e força que regulam a coesão.

Como relação, o Estado constitui, segundo o autor, um 264 processo histórico político em construção marcado por momentos de estabilidade, mas também por períodos de transição e de mudança. A estabilidade é definida por fases nas quais hierarquias, hábitos e procedimentos se desenvolvem de forma previsível. Linera problematiza os momentos de ruptura dessa regularidade como crise do Estado, que quando total, implica mudança de estruturas de poder e dominação, expressando-se por meio de cinco elementos ou etapas:

a. a da sua develação, quando emerge uma dissidência ao sistema político dominante articulado em um bloco com capacidade de mobilização e expansão territorial. Isto é, um projeto de poder emergente.

b. a do empate catastrófico: a partir de Gramsci, Linera identifica essa etapa como caracterizada pelo momento no qual a consolidação da dissidência se constitui em um projeto nacional cuja incorporação ao discurso dominante se torna impossível e que apresenta 
capacidade de disputar, pelo menos parcialmente, o controle territorial do bloco político dominante. Nesse ponto, a sociedade, argumenta o autor, começa a construir mecanismos alternativos de legitimidade.

c. a da renovação ou substituição radical de elites políticas: esta se produz no momento no qual o bloco dirigente desses setores sociais articulados em torno ao projeto emergente, ascende ao governo.

d. a da construção, reconversão ou restituição conflitiva de um bloco de poder econômico, político e simbólico: caracterizada pelo autor como a etapa de efetiva constituição do Estado como ferramenta de contenção e de consolidação dos ganhos do bloco emergente. O momento da busca por "juntar o ideário da sociedade mobilizada com a utilização dos recursos materiais do ou desde o Estado" (García Linera, 2013, p. 87 , tradução nossa) ${ }^{20}$

e. a do ponto de bifurcação: presente em todos os processos de transformação revolucionária, constitui o momento da pura medição de forças. Sem estar mediada pelos processos de construção de legitimidade e de consenso, a política se define como um ato de força. Poder-se-ia afirmar que marca o início do processo de resolução da crise política do Estado no sentido de que se trata do momento de tensão definitiva, no qual ou se consolida a nova estrutura de poder ou se reconstitui o bloco precedente.

No caso de se avançar no sentido da transformação, consolida-se a transição, levando à transformação de uma forma estatal caracterizada por uma nova coalizão social, afirmada hierarquicamente e acompanhada por uma nova burocracia estatal. A estabilização da nova ordem depende, então, do estabelecimento de uma configuração diferente da estrutura

20 No original: "ensamblar el ideario de la sociedad movilizada con la utilización de los recursos materiales del o desde el Estado". 
das relações materiais e institucionais, assim como também de um novo padrão ideacional.

No caso boliviano, nos ilustra García Linera, a vitória simbólica das forças da mudança expressa-se no fato de que, em que pese a reação ideológica-conservadora, o sentido comum ordenador do campo político e intelectual passou a se organizar localizando no centro do debate três eixos fundamentais da nova forma estatal: desconcentração territorial do poder, presença do Estado na economia e pluralismo cultural. Esse último ponto supõe o reconhecimento do que o autor denomina a diversidade do Estado, a pluriculturalidade ou plurinacionalidade como novo eixo do ordenamento simbólico. ${ }^{21}$

\section{Comparação e balanço das teorias}

Como salientado na introdução, a ideia central deste artigo é que, embora em diferentes planos sobre os quais centram sua reflexão e sua ação, as obras de Cox e García

266 Linera compartilham os elementos estruturais de suas estruturas analíticas.

Dois aspectos essenciais desse exercício de comparação chamam atenção: (1) o foco de Cox concentra-se no universal e o de Linera no local, mas ambos não negligenciam a interrelação das duas dimensões; e (2) a ênfase de Cox está em decifrar a ordem vigente e seus mecanismos de reprodução enquanto Linera busca entender, para além dos elementos constitutivos do poder (status quo), a dinâmica de sua superação.

Respeitando a tradição marxista, os autores pensam as relações sociais como núcleo básico da análise. Identificam que, no sistema capitalista, a disputa central é pela apropriação do excedente econômico, o que configura uma sociedade estruturalmente irreconciliável em termos de classes sociais em disputa. Influenciados decisivamente pela obra

\footnotetext{
${ }^{21}$ A experiência escrita nessa etapa da produção intelectual de Linera está plasmada pela ascensão ao poder dos subalternos e ainda não capta a ruptura que implica a restauração da velha ordem, o que viria a ocorrer em 2019.
} 
de Gramsci, os dois salientam a dimensão ideológica/cultural das relações de poder, o que implica em dar centralidade à questão da legitimidade da ação.

Preocupam-se com os elementos da regularidade, das características estruturais da ordem, para pensar a transformação. Nesse sentido, pode-se dizer que Cox analisa de forma mais aprofundada a dimensão da continuidade tendo como imperativo teórico a mudança. Por sua vez, em Linera, a transformação é um "imperativo categórico", ocupa um espaço de maior relevância, sobretudo ao aplicar as categorias para pensar o processo político boliviano que tem no autor um dos seus protagonistas. Aqui, ação e reflexão se plasmam, o que se reflete na construção teórica do autor.

A regularidade trabalhada por Cox através do conceito de ordem está definida pela padronização de interações que expressam certa coerência, pela estrutura histórica e os mecanismos de reprodução institucional, material e ideacional do poder. Uma formulação semelhante em García Linera é a de estabilidade, que acontece quando as relações se desenvolvem de forma previsível, sustentadas sob um complexo de hierarquias, de hábitos e de procedimentos. A proposta analítica de Cox é a de pensar a ordem em função do conceito de estrutura histórica enquanto García Linera refere-se a estruturas de poder e dominação. Em ambos os casos, a reflexão sobre as características das estruturas se identifica como elemento fundamental para encarar os projetos de mudança. Isso se apresenta, com especial clareza, no suposto de Cox de que essas estruturas configuram os marcos para a ação.

Provavelmente um dos pontos que diferenciam os dois esquemas analíticos tem a ver, precisamente, com a caracterização dessas estruturas. Nos dois casos existe uma composição de três elementos. Para Cox esses são: ideais, capacidades materiais e instituições. Para García Linera, por outro lado, a análise também combina três elementos interconexos, mas seguindo uma configuração diferente. 
Como exposto, para García Linera os elementos materiais e institucionais conformam uma mesma dimensão da análise, configurando materializações de ações passadas. Nesse sentido, pode-se afirmar que, embora a proximidade salientada, os autores utilizam princípios analíticos diferentes. Cox categoriza as forças, os componentes das estruturas históricas, em função da especificidade na qual se funda sua capacidade de constrangimento para a ação.

Embora seguindo um sentido semelhante, García Linera adota um caminho alternativo, classificando as dimensões em função da temporalidade. Isso porque o autor enfatiza que se trata de processos em construção permanente, razão pela qual é preciso diferenciar entre as "materializações passadas dessas inter-relações referidas à dominação e à legitimação política" e os fluxos de inter-relações. Dessa forma, no esquema de García Linera, as três dimensões de análise são a material-institucional, a ideal-simbólica e a da correla268 ção de forças. Assim, um dos pontos mais interessantes do esquema proposto pelo autor é o fato de que os sujeitos políticos, os blocos em disputa, são localizados no centro da análise sobre as características da ordem vigente.

Propomos, a seguir (Figura 1), uma síntese figurativa do esquema de Linera, para efeito de comparação pelo esquema proposto por Cox (2001):

\section{Figura 1}

\section{Comparação entre os esquemas de Linera e Cox}

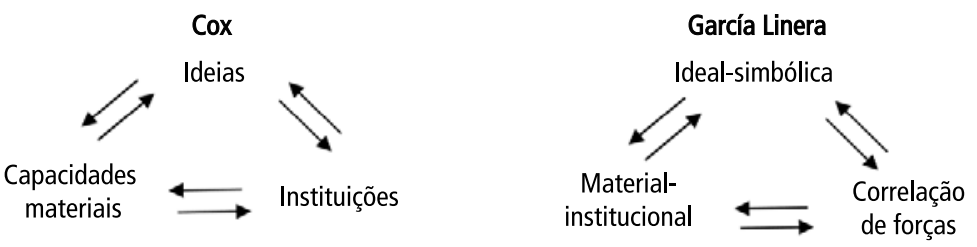

Fonte: Elaboração própria.

Cox, por sua parte, considera a dimensão dos atores políticos ao identificar os três níveis de análise aos quais 
pode-se aplicar o método das estruturas históricas. O primeiro deles, o das forças sociais, tem a ver precisamente com as características políticas dos diversos grupos sociais. O segundo é o da forma estatal e o terceiro o das ordens mundiais. Assim, esses últimos dois níveis guardam uma marcada proximidade com o proposto por García Linera. Como referido na seção anterior, esse autor diferencia as relações seguindo um princípio classificador ligado à espacialidade na qual elas se desenvolvem. Nesse sentido, seu esquema se desenvolve em dois níveis: o das relações territorializadas, aquelas que se caracterizam fundamentalmente por terem sua espacialidade definida, e as que, por oposição, são definidas como desterritorializadas.

Assim, ao primeiro nível corresponde a relação-Estado que é representativa de um processo em permanente construção. O Estado, segundo García Linera, atravessa, então, momentos de mudança em suas formas e em seu conteúdo social que nos permitem diferenciar suas diferentes manifestações ao longo da história. Paralelamente, Cox define a forma estatal como aquela categoria emergente do estudo sobre o complexo Estado/sociedade civil. Também aqui se pensa um Estado em mutação e que apresenta características diversas ao longo do tempo, diversidade que pode se entender através do estudo das configurações específicas das estruturas históricas prevalecentes.

Embora com particularidades, os autores compartilham a percepção do processo de progressiva perda de autonomia relativa dos espaços nacionais nas últimas décadas. Cox estuda conjuntamente o que denomina internacionalização do Estado e internalização da produção, os quais se encontram logicamente associados. No que diz respeito à primeira questão, reflete sobre a emergência de estruturas corporativas, instituições internacionais (organizações e regimes), cuja capacidade de tomada de decisões se sobrepõe às formas institucionais nacionais. 
García Linera faz uma avaliação semelhante nesse sentido, pensando na existência de uma bidimensionalidade estatal-supraestatal, o autor argumenta que nas últimas décadas temos assistido a uma transformação da primeira derivada de um fortalecimento da segunda. Nesse sentido, salienta que, de forma progressiva, fluxos econômicos e políticos desterritorializados ganham capacidade de influência sobre as determinações de apropriação e de aplicação do excedente econômico a despeito das formas de organização nacionais.

Finalmente, a pluralidade é colocada por ambos como ideal de superação da ordem vigente. No caso de Cox e Schechter (2002), a pluralidade aparece na retomada do tema das civilizações, enquanto possibilidades legítimas de interpretação do mundo, de quadros mentais capazes de ordenar identidades, a partir das referências intersubjetivas. Nesse sentido, a pluralidade civilizacional é uma forma de resistência diante da totalidade discursiva apresentada 270 pela globalização e o hiperliberalismo. A pluralidade também pode gerar sínteses dialéticas, possibilidades, portanto, de novas práxis sociais que apontem para a superação da ordem capitalista vigente.

Em García Linera, isso pode se ver concretizado nas transformações efetivas acontecidas na Bolívia, durante o período da experiência do governo popular entre 2005 e 2019.

Provavelmente, o ponto mais expressivo dessa experiência tenha sido a nova Constituição que consagrou a Bolívia como um Estado Plurinacional. García Linera (2013, pp. 119-123) analisa a construção desse novo Estado em contraposição àquele que caracterizou o processo de criação do Estado nacional do século XIX. Esse, que rompia formalmente com o período colonial, manteve o núcleo central da forma colonialista: o desconhecimento a respeito das nações indígenas precedentes à República, dos seus direitos coletivos e dos seus sistemas político-culturais. Nesse sentido, a experiência contemporânea do governo popular na Bolívia 
representou, segundo o autor, uma tentativa de superação da identidade dominante homogeneizante, que transplantava uma cultura dominante, geográfica e originariamente distante, sobre os povos da Bolívia. A plurinacionalidade supõe um reconhecimento constitucional e institucional das nações indígenas originárias dentro do Estado, a construção de uma identidade nacional composta, que deriva na transformação de seu conteúdo social. Assim, nas palavras do autor, na Bolívia superou-se formalmente a relação de confronto Estado monocultural e uma sociedade plurinacional, com um Estado Plurinacional no qual a identidade dirigente reconhece as outras identidades nacionais.

Podemos concluir que a experiência boliviana, que embora incerta, porque em movimento e de forma ainda muito breve, possa ter sido um espaço concreto para a realização daquilo que Cox pensava para escala planetária: um mundo plural. Por sua vez, a transformação dessa pluralidade em combinação com a transformação qualitativa da distribuição das capacidades materiais exigiria um tempo mais longo de consolidação da experiência. Seria ingenuidade imaginar que um processo de ruptura possa ser realizado sem que as condições ideacionais e institucionais não estejam ancoradas em capacidades materiais de novo tipo, tanto destrutivas como construtivas. $\mathrm{O}$ exemplo boliviano também é eloquente nesse sentido, a ruptura "restauradora" de 2019 ainda é muito recente, e rompe com uma experiência de emergência cultural de nova base que, de certa maneira, manteve a materialidade capitalista anterior e não alterou fundamentalmente a estrutura de classes. Essa ruptura com a experiência popular nos faz intuir sobre o poder da ordem mundial sobre os espaços locais, principalmente quando a estrutura de classes não é rompida, e da incapacidade de se enfrentar as forças da reação sem uma adequada combinação das respectivas capacidades materiais construtivas e destrutivas. 
Este artigo não teve como objetivo fazer um balanço da experiência recente da política boliviana, mas elencar os elementos teóricos de dois pensadores que se propõe, a partir de espaços tão diferentes, pensar a superação da ordem capitalista. Assumimos que ambos dedicaram suficiente tempo de suas vidas para esse objetivo e que tinham plena convicção do tempo da longa duração dos processos de transformação civilizatórios. As convergências que se pode encontrar em ambos os autores mostram caminhos no sentido da emergência de práticas de ação coletiva com estratégias de longo prazo.

\section{Jaime Cesar Coelho}

Professor titular de Economia e Relações Internacionais na Universidade Federal de Santa Catarina (UFSC). Membro do Instituto Nacional de Ciência e Tecnologia para Estudos sobre os Estados Unidos (INCT-INEU).

\section{Laura Lacaze}

Licenciada em economia pela Universidade de Buenos Aires (UBA) e mestre em Relações Internacionais pela Universidade Federal de Santa Catarina (UFSC).

\section{Bibliografia}

ÁLVARO, Marcelo García Linera. 2015. Vicepresidencia del Estado Plurinacional de Bolivia, La Paz. Biografía. Disponível em: https://bit.ly/3qhzmns. [Indisponível]. Acesso em: 5 ago. 2016. COX, Robert W. 1987. Production, power, and world order: Social forces in the making of history. New York: Columbia University Press. v. 1.

COX, Robert W. 2001. Social forces, states, and world orders: beyond international relations theory. In: COX, Robert W.; SINCLAIR, Timothy J. (org.). Approaches to World Order. New York: Cambridge University Press. pp. 85-124.

COX, Robert W. 2007. Gramsci, hegemonia e relações internacionais: um ensaio sobre o método. In: GILL, Stephen (org.). Gramsci, materialismo histórico e relações internacionais. Rio de Janeiro: Editora da UFRJ. pp. 101-125. 
COX, Robert W. 2013. Universal foreigner: the individual and the world. Singapore: World Scientific Publish.

COX, Robert W.; SCHECHTER, Michael G. 2002. The political economy of a plural world: critical reflections on power, morals and civilization. Abingdon: Routledge.

FREITAS, Marcos Luã Almeida de. 2014. Cultura política indígena na Bolívia: o Tupakatarismo revolucionário da Ofensiva Roja de Ayllus Tupakataristas (1988-1991). Dissertação de Mestrado em História. Florianópolis: Udesc. Disponível em: https://bit.ly/3mjcUIp. Acesso em: 30 nov. 2020.

GARCIA, Ana S.; SÁ, Miguel Borba de. 2013. "Overcoming the Blockage": an interview with Robert W. Cox. Estudos Internacionais, v. 1, n. 2, pp. 303-318.

GARCÍA LINERA, Álvaro. 2010a. Forma valor y forma comunidad: aproximación teórico-abstracta a los fundamentos civilizatorios que preceden al Ayllu Universal. Buenos Aires: Prometeo Libros.

GARCÍA LINERA, Álvaro. 2010b. La construcción del Estado. Noticias, Facultad de Filosofia y Letras da Universidad de Buenos Aires, 8 abr. 2010. Disponível em: https:/ /bit.ly/3loMQKK. Acesso em: 30 maio 2016. GARCÍA LINERA, Álvaro. 2013. Democracia Estado Nación. La Paz: Vicepresidencia del Estado Plurinacional de Bolivia.

GARCÍA LINERA, Álvaro. 2015. Estado, democracia y socialismo. Rebelión, S. l., 19 fev. 2015. Disponível em: https://bit.ly/31l51AR. Acesso em: 30 nov. 2020.

STEFANONI, Pablo. 2009. Álvaro García Linera: pensando Bolivia entre dos siglos. In: GARCÍA LINERA, Álvaro. La potencia plebeya: acción colectiva e identidades indígenas, obreras y populares en Bolivia. 2. ed. Bogotá: Siglo del Hombre Editores. pp. 9-26.

VICEPRESIDENCIA DEL ESTADO PLURINACIONAL DE BOLIVIA. 2010. I Ciclo de seminarios internacionales: Pensando el mundo desde Bolivia. La Paz: Instituto Internacional de Integración del Convenio Andrés Bello.

VICEPRESIDENCIA DEL ESTADO PLURINACIONAL DE BOLIVIA. 2011. II Ciclo de seminarios internacionales: Pensando el mundo desde Bolivia. La Paz: Instituto Internacional de Integración del Convenio Andrés Bello. 


\section{INSURGÊNCIA PERIFÉRICA E A TEORÍA CRÍTICA DAS RELAÇÕES INTERNACIONAIS}

JAIME CESAR COELHO E LAURA LACAZE

Resumo: Este artigo tem como objetivo central estabelecer um diálogo entre as obras de García Linera, pensador marxista e político boliviano, e Robert W. Cox um dos fundadores da teoria crítica de relações internacionais. Observa-se que os escritos de ambos os autores têm como elemento normativo comum uma perspectiva antissistêmica, orientada a pensar o potencial para a transformação desde uma perspectiva igualitária (econômica) e plural (o respeito às diferentes formas culturais de organização da vida social). O diálogo que se propõe tem como metodologia um estudo comparado das partes constitutivas daquilo que podemos chamar de ordem (status quo) e os elementos concretos de sua transformação nessa tensa relação (dialética) entre o local e o universal, entre o doméstico e o externo, referidos nas obras dos respectivos autores. Trata, portanto, de economia e de poder, de sociedade e de estado, de resistência e de transformação, de ordem e de revolução. Trata das potencialidades e dos limites da contestação periférica da ordem internacional.

Palavras-chave: Teoria Crítica de Relações Internacionais; Insurgência; Periferia e Dependência.

\section{PERIPHERAL INSURGENCE AND THE CRITICAL THEORY OF INTERNATIONAL RELATIONS}

Abstract: This article dialogues between the works of Garcia Linera, a Marxist thinker and Bolivian politician, and Robert Cox, one of the founders of the critical theory of international relations. Both authors showed an anti-systemic perspective as common normative element, focused on thinking the potential for transformation from an (economically) egalitarian and plural (pertaining to the different 
cultural forms of social organization of life) perspective. This a comparative study of the constituent parts of what we can call order (status quo), and the concrete elements of its transformation in this tense (dialectical) relation between local and universal, between domestic and external, referred to in the works of the respective authors, and as such this paper talks about economy and power, society and state, resistance and transformation, order and revolution. It deals with the potentialities and limits of the peripheral contestation of international order.

Keywords: Critical International Relations Theory; Uprising; Dependence and Periphery.

Recebido: 24/04/2018Ａprovado: 09/10/2020 